\title{
'Venous lakes' - a corrosion cast scanning electron microscopy study of regular and myomatous human uterine blood vessels
}

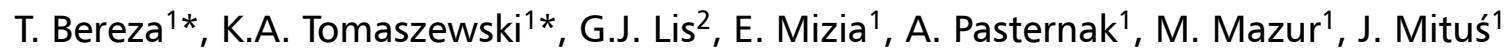 \\ ${ }^{1}$ Department of Anatomy, Jagiellonian University Medical College, Krakow, Poland \\ ${ }^{2}$ Department of Histology, Jagiellonian University Medical College, Krakow, Poland
}

[Received 11 August 2013; Accepted 30 October 2013]

Background: The aim of this study was to evaluate the venous structure of regular and myomatous human uteri, using corrosion casting and scanning electron microscopy (SEM). Special attention was paid to the endometrium and the so called 'venous lakes'.

Materials and methods: Uteri collected at autopsy $(n=67)$ were injected with Mercox CL-2R resin, which penetrated the capillary bed and filled both arteries and veins. After the polymerisation of the resin, the corrosion was performed. The obtained vascular casts, visualising all vessels including capillaries, were examined using scanning electron microscopy.

Results: Amongst the 67 uteri prepared for the corrosion casting, only 22 (15 containing leiomyomata) yielded casts of acceptable quality for SEM assessment. Veins of the endometrium and the myometrium were present in the form of a chaotic network, which did not run parallel to the arterial system, but was rather independent. Microscopic venous dilations ('venous lakes') were observed both within the functional layer of the endometrium and the myometrium. They were digit-like in shape and could be compared to venous sinuses. They drained the subendothelial capillary plexus and were supplied by numerous capillaries and venules. Their size ranged from 270 to $420 \mu \mathrm{m}$. Those dilatations were absent in the outer myometrium and the perimetrium, as well as the uterine cervix. We have not observed any arteriovenous anastomoses.

Conclusions: The myomatous uteri tend to have larger venous lakes than the normal uteri. The number and size of venous lakes increases with menstrual cycle progression. Further data on morphology and changes in venous lakes using scanning electronic microscopy should be acquired. (Folia Morphol 2014; 73, 2: 164-168)

Key words: venous lakes, ultrasonography, corrosion casting, scanning electron microscopy, uterus

Address for correspondence: K.A. Tomaszewski, MD, Department of Anatomy, Jagiellonian University Medical College, ul. Kopernika 12, 31-034 Kraków, Poland, tel/fax: +48 1242295 11, e-mail: krtomaszewski@gmail.com

*Contributed equally to this work. 


\section{INTRODUCTION}

Human uterine endometrium can be divided into 2 major layers - the superficial stratum functionalis, forming most of its thickness, and the stratum basalis, lying close to the myometrium. The chief structural feature distinguishing those 2 is their arrangement of blood vessels. Arteries penetrating the uterine wall form plexuses and - in the myometrium - give off smaller arteries and arterioles, which pass radially into the endometrium. At first, in the basal stratum, the vessels run straight. But as they progress more apically, they become tortuous and finally give off numerous side branches. Those supply the capillary plexuses, which are especially rich near the surface of the mucosa [14]. In the primate endometrium, 4 zones were distinguished by Bartelmez et al. [2-4]. From lumen to base, zone I (surface epithelium and adjacent stroma) and zone II (containing unbranched glands) form the functional stratum, while zone III (branched portions of glands) and zone IV (bases of glands) form the basal stratum.

In 1937 Daron [9] briefly summarised his observations on the subject of uterine endometrial venous network of Macacus rhesus monkey and noted for the first time the presence of venous lakes.

The corrosion casting technique combined with scanning electron microscopy (SEM) is currently the best available method for morphological examination of vascular networks $[6,16]$. The injected resin fills all blood vessels, including capillaries, and SEM offers high resolution and quasi-3-dimensional images. Since this method has never been employed in the visualisation of human endometrial venous lakes, the present study has been undertaken to examine the vascular architecture of those structures $[13,15,16]$.

\section{MATERIALS AND METHODS}

Sixty-seven uteri of women aged $25-56$ years were obtained upon autopsies performed at the Department of Forensic Medicine (Jagiellonian University Medical College). Women who died due to disorders of the reproductive system were not included in the study. Forty-three obtained uteri contained large subserosal uterine leiomyomata. The study was approved by the Bioethics Committee of the Jagiellonian University Medical College (approval KBET/121/8/2007). The material was collected $6-24 \mathrm{~h}$ post mortem. Each uterus, together with the ovaries and the cervical portion of the vagina, was removed in such a way that relatively long fragments of uterine and ovarian vessels (arteries and veins) were retained [5].

Endometrium was dated based on serial sections stained with haematoxylin and eosin, which were blindly assessed by a specialist gynaecological pathologist. The subjects were divided into the early proliferative (days 5-7), mid proliferative (days 8-11), late proliferative (days 12-15), early secretory (days 16-19), mid secretory (days 20-23), late secretory (days 24-27), menstrual (days 28-4) phases of the cycle.

Immediately after the removal, the uteri were perfused via the afferent arteries with pre-warmed $\left(37^{\circ} \mathrm{C}\right)$, heparinised saline $(12.5 \mathrm{lU} / \mathrm{mL}$ heparin; Polfa, Poland, containing 3\% dextrane (70 kDa) and $0.025 \%$ lidocaine (Lignocaine; Polfa), until the fluid outflowing via the veins was completely transparent ( $\sim 5 \mathrm{~min}$ ). Next perfusion was continued using a solution of $0.66 \%$ paraformaldehyde/0.08\% glutaraldehyde (Sig$\mathrm{ma}$ ) in $0.1 \mathrm{~mol} / \mathrm{L}$ cacodylate buffer, $\mathrm{pH} 7.4$, supplemented with $0.2 \%$ lidocaine. Finally, the vascular system was injected with $60-80 \mathrm{~mL}$ of Mercox CL-2R resin (Vilene Comp. Ltd. Japan), containing $0.0625 \mathrm{mg} / \mathrm{mL}$ methyl acrylate polymerisation initiator (Vilene Comp. Ltd.), and the uteri were left in a warm water bath $\left(56^{\circ} \mathrm{C}\right)$ for several hours to allow polymerisation and tempering of the resin $[20,21]$.

When the polymerisation was completed, the uterine tissues were macerated for 5-6 days by repeated baths in $10 \%$ potassium hydroxide at $37^{\circ} \mathrm{C}$ followed by washing with warm $\left(50-55^{\circ} \mathrm{C}\right)$ running tap water. The obtained vascular casts were washed for the next 4-5 days in multiple changes of distilled water under mild vacuum conditions, cleaned in 5\% trichloroacetic acid for 1-2 days, washed again in distilled water for 2-3 days and freeze-dried in a lyophilizer (Liovag G2; Aqua Fina, Germany) [23].

The freeze-dried casts were examined macroscopically, gently dissected [22] to expose the vasculature of endometrium and stored in an exicator containing phosphorus pentoxide until the microscopic examination. They were then mounted onto copper plates using colloidal silver and 'conductive bridges', and coated with gold [17]. The casts were examined using a JEOL SEM 35-CF SEM at 20-25 kV.

\section{RESULTS}

Amongst the 67 uteri prepared for the corrosion casting, only 22 (15 containing leiomyomata) yielded casts of acceptable quality for SEM assessment. The final 22 specimens came from premenopausal women 


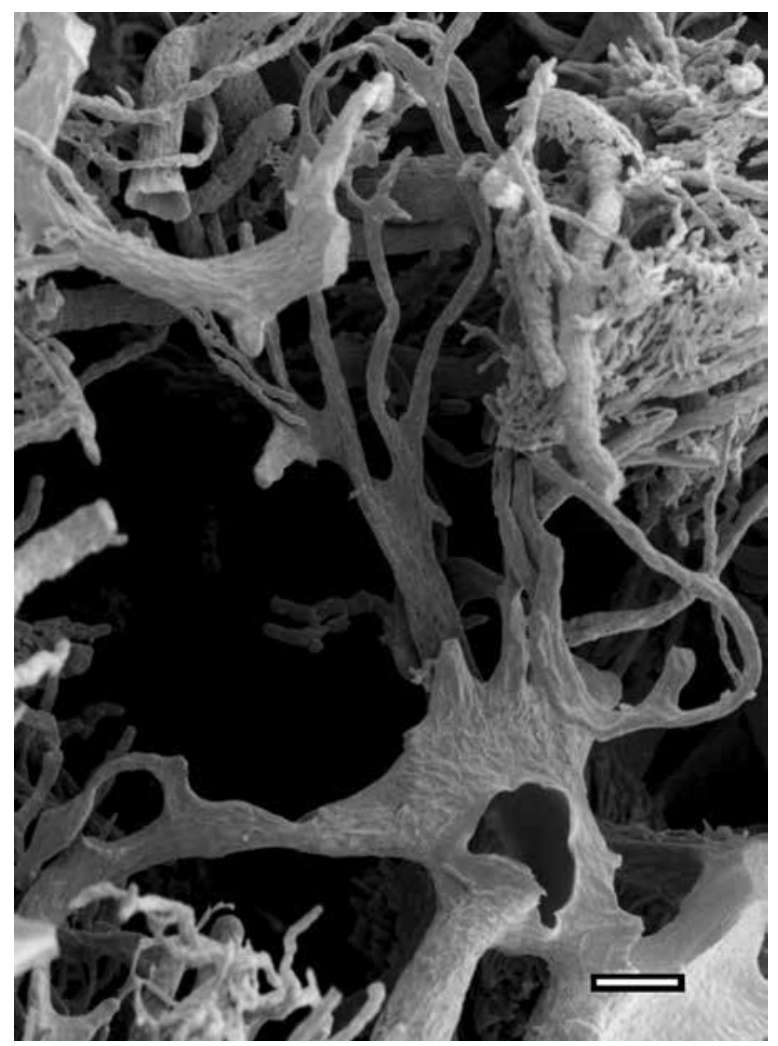

Figure 1. Uterus of 46-year-old female. Corrosion cast. Venous lake $(\sim 420 \mu \mathrm{m})$ with capillaries and small venules; SEM; Bar $=100 \mu \mathrm{m}$.

aged 25-46 years. The specimens were divided into the early proliferative $(n=3)$, mid proliferative $(n=5)$, late proliferative $(n=2)$, early secretory $(n=4)$, mid secretory $(n=2)$, late secretory $(n=3)$, menstrual $(n=3)$ phases of the cycle.

The venous vessels were usually accompanied by arteries running through the myometrium and endometrium of the uterus. The examined uteri contained the endometrium which was 3.6-8 $\mathrm{mm}$ thick. It consisted of a chaotic network of blood vessels - mostly capillaries, arterioles and venules. We have noted the presence of venous vessels dilatations $(\sim 150 \times 420 \mu \mathrm{m})$, which had the form of digital flattenings giving off few side branches (Fig. 1). Numerous venules (35-80 $\mu \mathrm{m})$ and capillaries $(\sim 16 \mu \mathrm{m})$ anastomosed with described venous dilatations (Fig. 2). All noted venous lakes were observable usually in the middle $1 / 3$ of the endometrium, although some were present close to the myometrium (Fig. 3). Venous lakes were represented abundantly in all of the specimens, and were found to be much larger in the secretory phase than in the proliferative one. Particularly large lakes were found in those specimens, where the en-

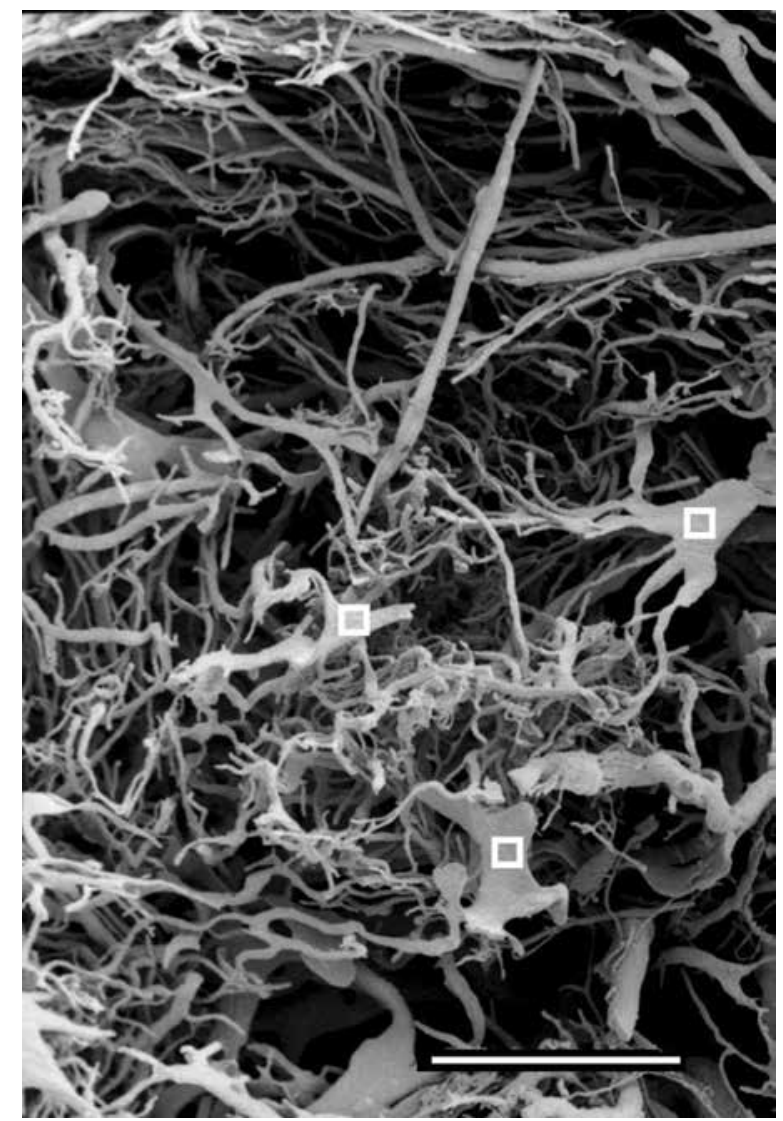

Figure 2. Venous lake with capillaries and small venules marked with 'squares' ( $235-80 \mu \mathrm{m})$; SEM; Bar $=1000 \mu \mathrm{m}$.

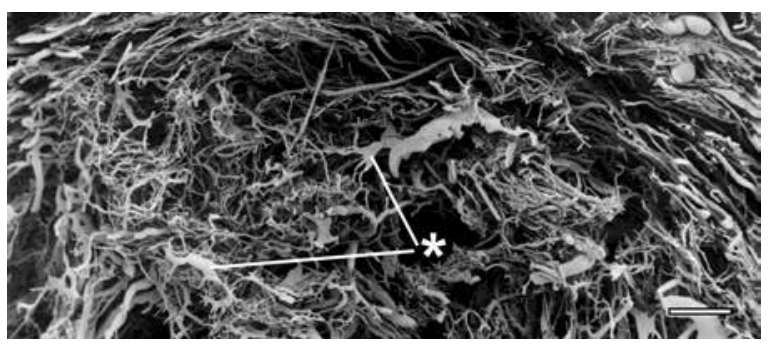

Figure 3. Uterus of 45 -year-old female. Corrosion cast. Venous lakes marked with asterisk $(\sim 230 \times 390 \mu \mathrm{m})$; SEM; Bar $=1000 \mu \mathrm{m}$.

dometrium has undergone simple hyperplasia. This was confirmed after examining the vasculature of 3 myomatous uteri. As the menstrual cycle progressed, the number and size of venous lakes increased, especially approaching the lamina epithelialis. In the premenstrual phase, venous lakes were abundant not only in the functional layer of the endometrium, but also directly below the surface of the epithelium. No arteriovenous anastomoses were found in the 
study material. No venous lakes were observed in the uterine cervix.

\section{DISCUSSION}

This study has been undertaken to visualise, using corrosion casting combined with SEM, the venous structure of regular and myomatous human uteri, with special attention paid to venous lakes.

In the present study, the resin was injected via arteries and filled the veins under low pressure after passing through the capillary bed. That is most probably why we have not observed artificial dilatations of veins, as reported in previous studies [10-12].

In his classic papers $[8,9]$, Daron described the endometrial venous system of Macaccus rhesus as a system of small veins, running parallel or centrifugally from the uterine lumen. The vessels do not unite into large basal trunks. He also observed numerous anastomoses. In the middle third of the endometrium he noted large venous lakes - i.e. enormously dilated veins at some anastomosis sites.

In his fundamental paper [19], Schlegel denoted that a uterus venous efflux apparently begins in 2 ways: 1 ) as venous capillaries, entering into venules, and 2) as venous lakes, which, in the injected specimens, appear as blue plaques varying in size (depending on cycle phase) and are drained by venules. He observed numerous capillaries that opened directly into such venous lakes, which undoubtedly may be looked upon as venules that have been dilated because of relatively high pressure. In our study, venous lakes were found in the entire functional part of the endometrium. In specimens nearing the menstrual phase, they were observed even directly beneath the lamina epithelialis. Here they may become very large, presumably up to $100 \mu \mathrm{m}$ in diameter. The venules draining these venous lakes and the capillary network run centrifugally from the uterine cavity, forming numerous anastomoses, and in the compact layer, during the secretory phase, they were rather swollen.

We have noted that the size of venous lakes is larger in specimens that have undergone hyperplasia (myomatous). The number of the investigated structures also increases with the progression of the menstrual cycle. However, in the current study, the number of examined specimens does not allow to draw general conclusions in that matter. This can be regarded as one of the drawbacks of the present study.

Buletti et al. [7] injected specimens with coloured latex and noted that venous vessels can form large dilatations - the so called 'venous lakes'. He found that they are more numerous at early and midluteal phases. They were flowing into one another and to the basal veins, that join the venous internal plexus, and finally the uterine veins.

Nearly seventy years ago, Daron $[8,9]$ noted the presence of the so called 'venous lakes' in the endometrium. Bulletti et al. [7] stated that the most important morphological changes occur on spiral and arcuate arteries, as well as on venous lakes. Further data on the morphology and variations of the venous lakes, using SEM, should be acquired.

In this study, fresh uterine specimens from hysterectomised patients could not be used, because complete organs are required for proper resin injection. Normally, after surgery, at least fragments of the removed uterine tissue must be collected for histopathological examination. The application of corrosion casting and SEM to autopsy material bears a risk of poor tissue preservation. Only single papers report successful casting of such material $[1,18]$. This obviously limits corrosion casting studies of human tissues and organs. However, we were able to obtain acceptable casts from $\sim 35 \%$ of uteri collected upon autopsy $6-24 \mathrm{~h}$ post mortem. This demonstrates that, considering all the limitations, this technique can be successfully applied to human organs obtained during autopsy.

\section{CONCLUSIONS}

Concluding, myomatous uteri tend to have larger venous lakes than normal uteri. The number and size of the venous lakes increases with the progression of the menstrual cycle. Further data on the morphology and changes in the venous lakes using SEM should be acquired.

\section{ACKNOWLEDGEMENTS}

The authors wish to thank J. Kołodziej, MD, (Department of Forensic Medicine, Jagiellonian University Medical College) for his cooperation in collecting the material, and M. Nowogrodzka-Zagorska, PhD, for skilled technical assistance.

\section{FUNDING}

This study was funded by means of Jagiellonian University Medical College statutory funds.

\section{REFERENCES}

1. Banya $Y$, Ushiki T, Takagane $H$, Aoki $H$, Kubo $T$, Ohhori $T$, Ide $C$ (1989) Two circulatory routes within the human corpus 
cavernosum penis: a scanning electron microscopic study of corrosion casts. J Urol, 142: 879-883.

2. Bartelmez GW (1957) The form and the functions of the uterine blood vessels in the rhesus monkey. Carnegie Contrib to Embryol, 249: 153-209.

3. Bartelmez GW (1956) Premenstrual and menstrual ischemia and the myth of endometrial arteriovenous anastomoses. Am J Anat, 98: 69-95.

4. Bartelmez GW, Corner GW, Hartman CG (1951) Cyclic changes in the endometrium of the rhesus monkey. Carnegie Contrib. to Embryol, 227: 99-144.

5. Bereza T, Tomaszewski KA, Bałajewicz-Nowak M, Mizia E, Pasternak A, Walocha J (2012) The vascular architecture of the supravaginal and vaginal parts of the human uterine cervix: a study using corrosion casting and scanning electron microscopy. J Anat, 221: 352-357.

6. Bereza T, Tomaszewski KA, Walocha J, Mizia E, Bachul P, Chmielewski P (2012) Vascular architecture of the human uterine cervix, as assessed in light- and scanning electron microscopy. Folia Morphol, 71: 142-147.

7. Buletti $C$, Jasonni VM, Tabanelli S, Ciotti $P$, Vignudelli $A$, Flamigni $C$ (1985) Changes in the uterine vasculature during the menstrual cycle. Acta Eur Fertil, 16: 367-371.

8. Daron GH (1936) The arterial pattern of the tunical mucosa of the uterus in Macaccus rhesus. Am J Anat, 58: 349-419.

9. Daron GH (1937) The veins of the endometrium (Macacus rhesus) as a source of the menstrual blood. Anat Rec, 67: 13.

10. Farrer-Brown G, Beilby JOW, Tarbit MH (1970b) The vascular patterns in myomatous uteri J Obstet Gynecol, 77: 967-975.

11. Farrer-Brown G, Beilby JOW, Tarbit MH (1971) Venous changes in the Endometrium of Myomatous Uteri. Obstet Gynecol, 38: 743-751.

12. Faulkner RL (1945) An injection study of uterine blood vessels. Amer J Obstet Gynec, 49: 1-6.

13. Hickey M, Fraser I (2003) Human uterine vascular structures in normal and diseased states. Micr Res Tech, 60: 377-389.
14. Hickey M, Fraser IS (2000) The structure of endometrial microvessels. Hum Reprod, 15: 57-66.

15. Kaiserman-Abramof IR, Padykula HA (1989) Angiogenesis in the Postovulatory Primate Endometrium: the Coiled Arteriolar System. Anat Rec, 224: 479-489.

16. Lametschwandtner $A$, Lametschwandtner $U$, Weiger $T$ (1990) Scanning electron microscopy of vascular corrosion casts - technique and application: updated review. Scanning Microsc, 4: 889-941.

17. Lametschwandtner $A$, Miodoński A, Simonsberger $P$ (1980) On the prevention of specimen charging in scanning electron microscopy of vascular corrosion casts by attaching conductive bridges. Mikroskopie, 36: $270-273$.

18. Murakami T, Fujita T, Tanaka T, Tsubouchi M, Tsubouchi Y, Taguchi T, Ohtsuka A, Kikuta A (1994) Microcirculatory patterns in human pancreas: supplementary observations of vascular casts by scanning electron microscopy. Arch Histol Cytol, 57: 9-16.

19. Schlegel JU (1946) Arteriovenous anastomozes in the endometrium in man. Acta Anat, 1: 284-325.

20. Walocha JA, Litwin JA, Bereza T, Klimek-Piotrowska W, Miodoński AJ (2012) Vascular architecture of human uterine cervix visualized by corrosion casting and scanning electron microscopy. Hum Reprod, 27: 727-732.

21. Walocha JA, Litwin JA, Miodoński AJ (2003) Vascular system of leiomyomata revealed by corrosion casting and scanning electron microscopy. Hum Reprod, 18: 1088-1093.

22. Walocha JA, Miodoński AJ, Nowogrodzka-Zagórska M, Kuciel R, Gorczyca J (2002) Application of a mixture of glycol polyethylenes for the preparation of microcorrosion casts: an observation. Folia Morphol, 61: 313-316.

23. Walocha JA, Miodoński AJ (2004) Angioarchitektonika naczyń żylnych endometrium mięśniakowatej macicy ludzkiej: badania w mikroskopii skaningowej. Ginekol Pol, 75: 853-857. 